\title{
GEOGRAFÍA Y SOCIEDADES TRADICIONALES DEL GRAN CHACO
}

\author{
Alfredo Tomasini y José Braunstein
}

\section{A Horacio Difrieri. In memoriam}

El fin de esta sinopsis es el intento de proveer elementos para que el lector pueda enmarcar, desde una perspectiva espacio-temporal, la rica información sobre los indígenas del Gran Chaco que hoy se posee. La necesaria brevedad que impone este objeto nos obliga a realizar un esfuerzo de simplificación y síntesis, salteando matices y diferencias que caracterizan a nuestra tarea de etnógrafos. Para efectuar esta obligada generalización hemos escogido un camino que intenta bosquejar -al margen del estado actual de la clasificación étnica de los pueblos de la región- simultáneamente, los aspectos fisiográficos del territorio y algunos de los rasgos culturales propios de los indios chaqueños que aparecen como particularmente ajustados a esa geografía.

La región chaqueña comprende la porción septentrional de las llanuras que Martin de Moussy (Frenguelli, 1943, pp. 29-30) llamó «Pampasia», incluyendo partes de Argentina, Bolivia y Paraguay. Se han establecido los siguientes límites: por el Norte el territorio de Chiquitos, donde la transición suele fijarse, de modo convencional, en la línea férrea que se extiende entre Santa Cruz de la Sierra (Bolivia) y Corumbá (Brasil); al oeste, la gran región andina, representada por las Sierras Subandinas y las Pampeanas; al sur pasa en transición gradual a la llanura pampeana en la zona comprendida entre la laguna de Mar Chiquita y la ciudad de Santa Fe; por el Este el río Paraguay y su continuación, el Paraná (Aparicio y Difrieri, 1981. Véase especialmente Vol. I, cap. 2: 3-170; ibidem: 191-201; Vol. II, cap. 2: 199-238). En general se considera que el término «Chaco» es de etimología quechua. En esa lengua existe un homófono que significa «cacería de batida», y que sirve también para designar al lugar o a la zona en que se practica la caza de esa manera. En este enorme territorio de más de un millón de kilómetros cuadrados no existen obstáculos reales para la comunicación humana, salvo las grandes distancias. Esto explica que -especialmente a partir de mediados del S. XVII, cuando varios grupos aborígenes adoptaron masivamente el caballo- los desplazamientos en el interior del Gran Chaco carecieron de otros límites que aquellos que estaban determinados por sus propias relaciones interétnicas. En lo atinente a la clasificación subregional del Gran Chaco, Fernando Pagés Larraya advirtió que «La geografía humana del Chaco ha tenido como organizador ecológico los ríos Pilcomayo, Bermejo y Salado, sobre los cuales se determinó la primera sistematización formal del Chaco, en Chaco austral, central y boreal, siendo los ríos Paraguay y, más al sur su continuación, el río Paraná, su preciso límite oriental y barrera ecológica humana, que adquirió sorprendentes significados en la endoculturación y transculturación de la zona»(Pagés Larraya, 1982, T.I: 121). La región chaqueña fue poblada, en una época aún no determinada de modo fehaciente, por un arcaico conjunto de grupos étnicos caracterizados desde tiempos prehistóricos -y, en parte, hasta hoy- por su existencia nómade o seminómade, 
acompañada por una organización económica basada en la caza, la pesca, la recolección de frutos silvestres y una agricultura rudimentaria.

El Chaco es una extensa planicie cuyo origen está vinculado con los procesos de fractura y descenso experimentados por la porción occidental del macizo de Brasilia durante la Era Terciaria. Dichos procesos determinaron una transgresión marina que cubrió gran parte de las llanuras chaqueña y pampeana. Durante el Plioceno, en una fase de ascenso, se produjo el retiro del mar y comenzaron a depositarse sedimentos de carácter continental. Desde el punto de vista topográfico, el Chaco constituye una extensa llanura de sedimentación, cuyas formas predominantes son lomadas anchas y chatas, y hondonadas que dan cabida a ríos, arroyos, lagunas, y zonas anegadizas con bañados y esteros. La pendiente general desciende desde el pie oriental de las montañas de la región andina hasta el eje de los ríos Paraguay y Paraná, con una suave inclinación de Noroeste a Sudeste. La marcada horizontalidad del Chaco determina una indecisión en el drenaje que ha provocado frecuentes cambios en el curso de los ríos. Estos han dejado numerosos cauces abandonados, llamados madrejones, que también indican la existencia en épocas pasadas, no muy lejanas, de una red hidrográfica más rica que la actual, correspondiente a un clima mucho más lluvioso. Las zonas de aguas estancadas, en los terrenos arcillosos, son los esteros, que constituyen un elemento característico del paisaje chaqueño. Por lo general desaparecen en gran parte durante el invierno, que es la estación seca, quedando solamente lagunas en las partes más profundas. Desde el punto de vista morfológico, Joaquín Frenguelli (op. cit., pp. 33-34) distinguió tres sectores en la llanura chaqueña que reflejan la estructura de los bloques cristalinos fracturados: la oriental o Chaco Bajo, la central o Chaco Deprimido y la occidental o Chaco Alto.

El agua signa, casi como un péndulo, al Chaco. Cuando no es por su abundancia enloquecida y sin reglas, lo es por su carencia agobiante. Durante el invierno raramente las escasas nubes vuelcan su contenido de humedad en las tierras sedientas y calcinadas por el trópico; de pronto, en octubre o noviembre, comienzan a derramarse los $900 \mathrm{~mm}$. de promedio que las estadísticas pluviométricas denuncian. Las últimas gotas caen en marzo o abril. En invierno la sed es el peligro que acecha en el desierto arbóreo. En esa época la mayor parte de la vegetación, reseca, adquiere tonalidades en las que prevalecen el pardo, el gris y el amarillo, mas sin que el verde se extinga por completo. Durante el verano retorna la vida a esa gran laguna interior que se originó en el más remoto Pleistoceno o en el Mioceno, y un manto de distintos tonos de verde cubre la superficie. Los ríos se desbordan y mudan sus cauces, las aguas se estancan o corren muy lentamente sobre la superficie chata y de pendiente casi indefinida, cuyos únicos accidentes notables son las cicatrices que dejaron otras aguas en tiempos más antiguos. Todo el Chaco es, periódicamente, un ancho espejo de agua con fondo barroso. Milenios de depósitos fluviales han formado extensas capas de arcillas impermeables -o poco menos- que favorecen ese estancamiento. En el Este las precipitaciones pueden llegar en verano hasta los $1200 \mathrm{~mm}$., mientras que disminuyen gradualmente hacia el Oeste hasta no sobrepasar los $600 \mathrm{~mm}$, y sólo vuelven a aumentar en las cercanías de las Sierras Subandinas. El sistema hidrográfico chaqueño tiene dos protagonistas que, como vimos, atraviesan la región con un rumbo general de $\mathrm{NO}$ a SE. Se 
trata del Bermejo y del Pilcomayo. El Salado del Norte -vale decir, la continuación del Pasaje-, que fluye por la franja que hemos señalado como límite austral, sigue su curso solitario sin que ningún afluente le ayude desde el Norte a mantener su caudal agonizante, siendo así el único curso de agua exorreico que atraviesa un vasto territorio endorreico. Los tres grandes ríos chaqueños desembocan en la margen occidental de la falla que constituye el cauce del sistema fluvial Paraguay-Paraná.

Los promedios termométricos estivales del Chaco boreal alcanzan los $24^{\circ}$. Aunque la similar duración de los períodos diurno y nocturno y la prevalencia de las masas oceánicas -común al hemisferio sur- tienden a disminuir la importancia relativa del factor de continentalidad y atemperan la amplitud de la variación térmica diaria, ésta es considerable, aumentando hacia el Oeste. Pero otros factores inciden además en el incremento de la variación térmica; entre ellos cabe señalar que la forma del relieve, que favorece los grandes desplazamientos de las masas de aire, es uno de los preponderantes. El ingreso periódico de aire frío del Sur que desplaza al cálido del Norte y del Noreste califica el clima del Chaco no sólo en lo que respecta a los valores térmicos, sino también a los de humedad relativa: el viento norte llega al Chaco con porcentajes muy bajos de agua y acarreando polvo, en tanto que las masas de aire australes suelen provocar la precipitación de las nubes de las capas altas al introducirse, a modo de cuña, debajo de ellas. Otro factor que influye decisivamente en el clima del área es la fuerte insolación relacionada con la diafanidad del aire que eleva la temperatura. Las heladas son también frecuentes, sobre todo en invierno. El tema mítico de "la destrucción por helada", muy frecuente antre las creencias de los indígenas chaquenses, que muchas veces ha sido interpretado como indicio de la procedencia austral de uno u otro pueblo, puede ser explicado sin dificultad por la presencia de este fenómeno.

El paisaje chaqueño debió de ser, una vez producidos los desecamientos de las extensas lagunas y bañados centrales, de monte bajo y de amplias sabanas de tipo estepario. Hoy, en cambio, las zonas central y occidental son ámbitos de monte cerrado, mientras en el Chaco oriental se mantiene la característica de la frecuente aparición de extensos palmares y zonas abiertas con alta vegetación herbácea. A lo largo de los ríos más importantes y en la parte oriental la vegetación afecta la forma de selva subtropical; mientras que la del sector occidental es designada "parque chaqueño". Se caracteriza por el predominio de árboles de maderas duras. A este fenómeno se refieren los ecólogos cuando notan que "...es una de las pocas regiones del mundo, donde entre la zona tropical y la templada, no hay desierto de por medio" (Morello, 1968: 1-3). El Chaco tiene el raro privilegio de ser una de las pocas zonas del mundo con semejantes condiciones geográficas que no se han transformado en un medanoso desierto, como los que se encuentran sobre las áreas continentales situadas en una latitud similar en todo el mundo. Una de las razones de esta virtud se encuentra precisamente en la vegetación. Esos árboles de maderas durísimas y crecimiento muy lento -y, por lo tanto, de reposición casi imposible- han permitido por su resistencia la conservación de tenores de humedad mínimos y la fijación de suelos en áreas muy extensas, impidiendo así el desecamiento total. De este modo, los agentes atmosféricos no convirtieron al suelo en una capa deleznable, a merced de los vientos; el 
mismo mantiene, por el contrario, ciertas condiciones de fertilidad. Estas han dado lugar a la existencia de una variada vida animal; y el hombre chaqueño también ha sabido adaptarse y sacar provecho de las características del medio.

Predominan las especies leñosas, formando bosques aislados o isletas rodeadas de pastizales, de algarrobos blancos o negros (Prosopis alba o nigra), quebrachos colorados en sus dos variedades principales (Schinopsis lorentzii y Schinopsis quebracho colorado), quebrachos blancos (Aspidosperma quebracho blanco), guayacanes (Caesalpinia paraguariensis), que llegan a superar los veinte metros de altura, y especies arbustivas como la bola verde (Capparis speciosa); hay también mistoles (Zyzyphus mistol), chañares (Geoffroea decorticans), palos santos (Bulnesia sarmientoi), palos borrachos o yuchanes (Chorisia insignis) y diversas especies de acacias espinosas. Hacia el Sudoeste aumenta la aridez, y ello se manifiesta en la vegetación, predominando allí cactáceas arbóreas y leguminosas con espinas. Se aprovechan los frutos de las grandes tunas como el quimil (Opuntia quimilo) y varios de Cereus que se mezclan con un sotobosque de epífitas y renovales de vinal (Prosopis ruscifolia) (Cabrera y Willings, 1973, pp. 72-3; Ragonese y Castiglioni, 1970, pp. 142-154). Un estudio sistemático de los diferentes tipos de asociaciones vegetales en el área es el de Morello, quien destaca que “...En el Chaco se puede seguir el gradiente térmico trópico-templado a lo largo de fajas homogéneas en cuanto a pluviometría, topografía, continentalidad, etc." (Morello, op. cit. pp: 1-3).

En la vida de los chaqueños la recolección tuvo siempre un papel primordial. Es, entre los nativos, una tarea femenina, salvo la recolección de miel silvestre que es una tarea masculina. Los más variados frutos y raíces silvestres, en un número extraordinario, son conocidos por estos indígenas en sus cualidades alimenticias, tintóreas u otras variadas. Se destacan por su importancia la recolección de los cogollos de las dos especies de palma chaqueña y de algunas bromeliáceas (chaguar o caraguatá), tanto con fines alimenticios cuanto textiles. El hilado de la fibra de caraguatá posee difusión general en el Chaco, y puede afirmarse que contribuye a la confección de casi la totalidad de los utensilios empleados para el acarreo, así como a la de un conjunto de instrumentos de fines variados, en tanto que está ausente la técnica de la cestería. El hilado de las bromeliáceas está indisolublemente unido, para estos indígenas, al sexo femenino. En el Chaco se conoce una decena de técnicas de redes de malla que son tejidos con esta fibra. Las grandes bolsas de acarreo para transportar el botín de la recolección, las masculinas para la cacería, las redes de pesca o las empleadas en el transporte del ajuar doméstico; las pequeñas bolsas individuales así como la banda sin fin para el transporte de las criaturas, se confeccionan con este material. Según la creencia de la mayoría de las tribus chaqueñas, las mujeres originarias que bajaron del cielo traían ya consigo las técnicas del hilado del caraguatá. Esta narrativa, que explica la existencia femenina -en particular ligada al tema del ciclo menstrual, derivado de la condición originaria de estos seres que poseían dientes vaginales- funda y justifica el ritual iniciático de las mujeres en el que éstas debían aprender y demostrar durante el período crítico su habilidad hilandera ligada a la mayoría de edad. El hilo tiene decenas de usos, inclusive es el material con que se practica uno de los esparcimientos más notables de estos pueblos, como son los diseños al modo de "cat's craddle". La búsqueda de miel fue siempre una de las principales 
actividades del hombre chaqueño, que sabe reconocer y aprovechar las diferentes variedades de melíferas (Meliponae y diveras especies de avispas) en la temporada propicia. En conexión con el comienzo de la fructificación de las plantas silvestres y señalando el inicio de la época de siembra que preanunciaba un nuevo ciclo de abundancia, algunos grupos celebraban anualmente la aparición de las Pléyades en el cielo nocturno.

El Chaco posee una rica fauna, y sobre su aprovechamiento estuvo basada en gran medida la economía de los grupos étnicos que lo habitaron. Zoogeográficamente, constituye la parte meridional del distrito Subtropical de Yepes y Cabrera (Cabrera y Yepes, 1960, I, p. 15), llamado "Parque Chaqueño" por Castellanos. Según estos autores, en él mora un conjunto faunístico abigarrado, que obedece tanto a la influencia de tipo tropical como de la subregión Patagónica en lo que respecta a sus asociaciones de llanura. Por ello explican la presencia de los tatúes de rabo molle (Cabassous) y el vampiro (Desmodus), cuya mayor dispersión es tropical, y la del pichiciego menor (Chlamyphorus truncatus) y el cuis chico (Microcavia australis), estos últimos típicos de la región patagónica. Entre los mamíferos se cuentan carniceros, edentados, cérvidos, gran variedad de roedores y marsupiales, etc. Se conocen tres variedades de pecarí, el labiado, el de collar y el quimilero; las corzuelas roja y parda, el ciervo de los pantanos, el venado de las pampas, el tapir americano, varios armadillos, desde el pequeño 'tatú bolita' hasta el enorme 'tatú carreta'; los dos grandes felinos americanos, el jaguar y el puma, así como numerosas variedades de felinos menores; el lobo de crin o aguará guazú, así como los osos hormiguero y melero. La variedad de aves es enorme, pero debe ser destacado el significativo papel que posee en la cultura de los chaqueños posee el ñandú (Rhea americana), que es la presa de caza por excelencia. Para darle muerte se lo acecha, utilizando un camouflage de ramas y aprovechando los días de viento norte, que hace menos perceptible la presencia del cazador. Además del avestruz americano, se encuentran varios miembros de las familias Tinamidae, Anatidae, Columbidae y, entre los de la Cracidae, a la charata, que contribuye sustancialmente a la alimentación de los chaqueños. La figuración ornitológica de la humanidad primordial es muy usual en la mitología, lo que evidencia la importancia de las aves para los nativos del área. La caza se realiza con arco y flecha al acecho; de ojeo con incendio de los campos, con trampas de lazo, de hoyo, de contrapuerta y de peso muerto. El arco es simple, de madera dura (usualmente Prosopis kuntzei), la flecha posee astil de caña de castilla (Arundo donax) o de un arbusto llamado "suncho". La punta era, antiguamente, de madera, de forma lanceolada o serrada y, desde tiempos recientes, de hierro, con emplumado tangencial o carente completamente del mismo. En el invierno, cuando los ríos se encuentran en su nivel más bajo, es cuando aparecen en abundancia los numerosos peces que los habitan, que durante el otoño y el invierno representan un elemento de gran significación para la alimentación de los indígenas que habitan cerca de sus márgenes. Entre otras variedades, el sábalo, el surubí, la boga, el bagre, el pacú y el dorado, todos de considerable tamaño, son presas muy apreciadas. Los métodos de pesca son tradicionales en los ríos chaqueños, ante todo el de la captura con red, que a menudo se complementa con el dique-trampa o 
barrage. En los esteros y lagunas es más frecuente la pesca con arco y flecha o con arpón. También se conocen -aunque hoy están en desuso- la pesca con nasa y el uso de cebos vegetales para atraer a los peces. La captura del pez en las horas más frías por sumersión del pescador con la red conocida como "de bolsa", es común a casi todas las tribus. El pescado se mata golpeándolo en la cabeza con una maza de madera y se lo ensarta a través de los ojos con una aguja también de madera, que se encuentra en un extremo de una cuerda. El otro extremo de ésta se amarra a la cintura del pescador; si la excursión ha sido fructífera, al final de la jornada una gran cantidad de pescados estará enhebrada a dicha cuerda, y así se los transportará hasta la orilla, donde las piezas cobradas serán evisceradas. Los indios del Chaco utilizaron, pero rara vez para la pesca, embarcaciones primitivas como la canoa monóxila de madera de palo borracho -en el curso medio e inferior de los ríos Pilcomayo y Bermejo- y el bote "pelota" hecho de pieles para atravesar ríos y bañados. La estación lluviosa es considerada por los chaqueños como un tiempo de abundancia. La pesca se realiza muy poco en los ríos durante esa época. Su práctica con red se torna imposible de realizar y los peces escasean, a la inversa de lo que acontece en la estación seca, cuando los esteros ven reducida su superficie y los ríos están en estiaje. En cambio, con el calor y las lluvias, el florecimiento y la madurez de los frutos hacen de la recolección y el cultivo generosas fuentes de alimento. La cacería también se realizaba a menudo en terrenos anegados.

Los frecuentes cambios del habitat determinaban también, junto con el agotamiento del medio, la tendencia al nomadismo del hombre chaqueño, que constantemente se desplazaba en busca de condiciones medioambientales más favorables. En el invierno, la escasez de alimentos vegetales determina una mayor significación de la pesca y de la caza. En tiempos pasados las bandas y tribus que moraban lejos de los ríos se descentralizaban para buscar su sustento dispersos en un amplio territorio, conformando unidades que se empequeñecían demográficamente a medida que los recursos disponibles se hacían más escasos. Al comienzo de la temporada de lluvias la vida de los chaqueños se hacía más estable. Normalmente cada banda permanecía durante el verano en sitios más o menos estables. Los ancianos cultivaban entonces las chacras. Se trata de una agricultura rudimentaria, cuya cosecha era semejante a la recolección de las plantas silvestres y cuyos principales utensilios fueron el palo cavador y la pala en forma de remo de hoja lanceolada y sus productos de mayor relevancia el tabaco, algunas cucurbitáceas como el zapallo y la calabaza confitera, porotos, mandioca y batata. Las calabazas eran usadas como recipientes con fines varios, tanto para líquidos como -tallándoles una tapa estrellada- para efectos personales, o para hacer sonajeros rellenándolas con semillas. Los sonajeros constituyen el instrumento predilecto para acompañar el canto masculino individual, tanto durante las prácticas shamánicas como durante ciertos bailes, usuales en periodos de reuniones festivas. Este instrumento musical normalmente no se decoraba, pero las calabazas destinadas a otros usos solían adornarse con pirograbados o incisiones, que consistían en motivos geométricos, o en representaciones naturalistas. En esta época tenían lugar fiestas cuyo motivo más llamativo estaba constituido por la ingestión de las cervezas preparadas a partir de la fermentación de los frutos de muchas plantas silvestres diferentes, en especial los algarrobos (Prosopis) y de la miel elaborada por las numerosas abejas silvestres del 
Chaco, esto es, la hidromiel.

La organización social de estos pueblos puede comprenderse a partir de la conformación de unidades que son básica y primordialmente locales. En la apropiación del territorio se distribuyen bandas -conceptualizadas como familias extensas- y relacionadas entre sí por intercambios y matrimonios. La asociación de esas bandas constituye un género de unidades sociales intermedias a las que hemos llamado "tribus". Cada una de estas sociedades, cuyas normas de linealidad pueden caracterizarse, en general, como bilaterales, y las de residencia postmatrimonial por la tendencia a habitar en el grupo local de la mujer, era la expresión máxima de unidad política cuya "tonicidad" dependía en la red de alianzas entre bandas, familias e individuos. Así descriptas, las tribus representan el espacio endogámico preferencial que podría ser expresado en frecuencias estadísticas.

En un trabajo anterior (Braunstein, 1983, pp. 81-96) se realiza una clasificación de las sociedades del Gran Chaco de acuerdo a los límites de las posibilidades matrimoniales expresados tendencialmente sobre la base de una normativa de proscripción de determinados vínculos. Se separaba así un grupo correspondiente a los "chaquenses típicos", del que se destacaba aún el caso de por lo menos algunas de las tribus matacas en las que el impedimento matrimonial no excede la proximidad de un solo vínculo parental del de otras en las que podía llegar hasta tres; uno correspondiente a los de habla Zamuco, caracterizados por una exogamia de sib (patrilineal) superpuesta a la exclusión matrimonial en el seno de la familia extensa (bilateral), similar a la norma del sustrato chaqueño; y un tercero, correspondiente a las etnias de filiación amazónica, resultante seguramente del ajuste de un modelo de parentesco de tipo dravidiano (caracterizado por la ecuación Hno.Ma = Pa.Ea), común en la olla amazónica, a las condiciones chaqueñas. Un estudio sistemático con metodología estadística de estas sociedades -en curso de realización- es necesario para caracterizar eficientemente estos modelos.

De cualquier modo, no existen patrones prescriptivos rígidos sino proscriptivos que marcan tendencias y los matices que se señalan para las diferentes unidades escapan al marco prefijado para este breve opúsculo. La considerable estabilidad de estas unidades determinó que exista una frecuente coincidencia entre estas tribus y las unidades lingüísticas del orden dialectal. Las bandas, más o menos aisladas pero vecinas, se reunían físicamente con cierta regularidad, sobre todo en verano. La iniciación femenina era usualmente el contexto ritual formalizado que otorgaba el marco ceremonial determinante de los encuentros entre los representantes de las diferentes bandas que integraban una tribu. Fuera de ellas, las etnias - distintas tribus que compartían una misma lengua- raramente mantenían una cohesión política, siendo en cambio más o menos frecuente la alianza de bandas de diferentes etnias, que formaban unidades tribales interétnicas que podían tener incluso una duración bastante prolongada. Este modelo se expresa a nivel regional en una red de alianzas y enemistades que tenía por motivo fundamental la lucha por determinados cazaderos o, con mayor frecuencia, pescaderos. La práctica del barrage de los ríos trajo muchos conflictos interétnicos, intertribales e, incluso, entre bandas de una misma tribu. La familia solía ser monogámica aunque la poliginia, a pesar de haber sido siempre rara, estaba permitida. La jefatura era determinada por consenso, y en varias etnias tenía su fundamento en el prestigio 
que los individuos adquirían como guerreros. La autoridad era bastante laxa y los jefes desempeñaban funciones especiales durante la guerra o para obtener en otras circunstancias la cohesión del grupo por medio de la oratoria.

La guerra era característicamente una guerra de sorpresas, asaltos y fugas; el principal trofeo era el skalp -esto es el cuero cabelludo- del enemigo muerto. El prestigio de un hombre solía estar ligado directamente al número de cueros cabelludos que poseía, es decir, a la cantidad de enemigos (indios de otras etnías o blancos) a los que había dado muerte. En torno a la guerra también se organizaba un complejo ritual que se relaciona directamente con la institución de la jefatura y las reuniones de bebida en las que los guerreros relataban sus hazañas. En algunos grupos, se festejaban los triunfos con la exposición de los cueros cabelludos de los enemigos muertos y se ejecutaban bailes rituales relacionados. Las relaciones entre los grupos estaban enmarcadas así por dos límites rituales: las ceremonias de iniciación con sus encuentros, danzas, regalos, etc. y la guerra, que también implicaba ceremonias periódicas y que no poseía una realidad de intercambio material mas sí genético, aunque menor, a través del robo y el rapto. Era más o menos frecuente la toma de prisioneros de guerra, pertenecientes a etnías enemigas. En muchos casos, esos individuos concluían por integrarse a la banda de sus captores. Como situacionas intermediarias, el difundido juego de jockey y un original juego de azar permitían a los chaqueños la integración, manteniendo a un nivel simbólico el lenguaje de la guerra. En efecto, representan explícita, pero acotadamente, una confrontación bélica y no eran pocas las veces que desembocaban en verdaderos combates o, a la inversa, permitían la paz entre los grupos.

A partir del siglo XVI, vale decir, desde el albor de la Conquista de América, misioneros, cronistas y viajeros nos han legado noticias y descripciones referentes a los aborígenes chaqueños. En 1567 fue fundada la ciudad de Nuestra Señora de Talavera, más conocida como Esteco, junto a la ribera del río Salado del Norte. En 1585 se organizó la de Concepción de Nuestra Señora, sobre el Bermejo, en pleno Chaco Austral. Joaquín Camaño y Bazán, un jesuita natural de la ciudad de Todos Santos de la Nueva Rioja, se encontraba exiliado en Faenza, Italia, después de la destrucción de la República Cristiana dispuesta por Carlos III de Borbón, cuando escribió una Noticia del Gran Chaco. En ella discriminó la existencia de trece "Naciones" indígenas que podían distinguirse por la peculiaridad de la lengua que hablaban, y confeccionó un mapa etnográfico de la región.

La Noticia del padre Camaño constituye la primera clasificación orgánica conocida de las etnias del Chaco y aún hoy posee un alto grado de validez (Furlong, Guillermo, 1955: 109-10 y 117-25). Posteriormente deben consignarse los aportes de G. Boggiani, T. Koch-Grünberg, R. Hunt y C. Loukotka que, apoyándose en la respectiva actualización de la información lingüística, completaron dicha clasificación hasta conformar el cuadro que se acepta actualmente y que se resume gráficamente en el siguiente mapa etnográfico del Chaco (Wilbert y Simoneau, 1982. Este diagrama fue confeccionado con la participación de uno de nosotros).

La clasificación cultural no es muy indicativa. El padre Guillermo Schmidt, sobre la base de los datos existentes en su época, incluyó a ese mosaico étnico en las 
Folia Histórica del Nordeste, $\mathbf{N}^{\circ} 16$ (Resistencia, 2006) IIGHI, CONICET - IH, UNNE)

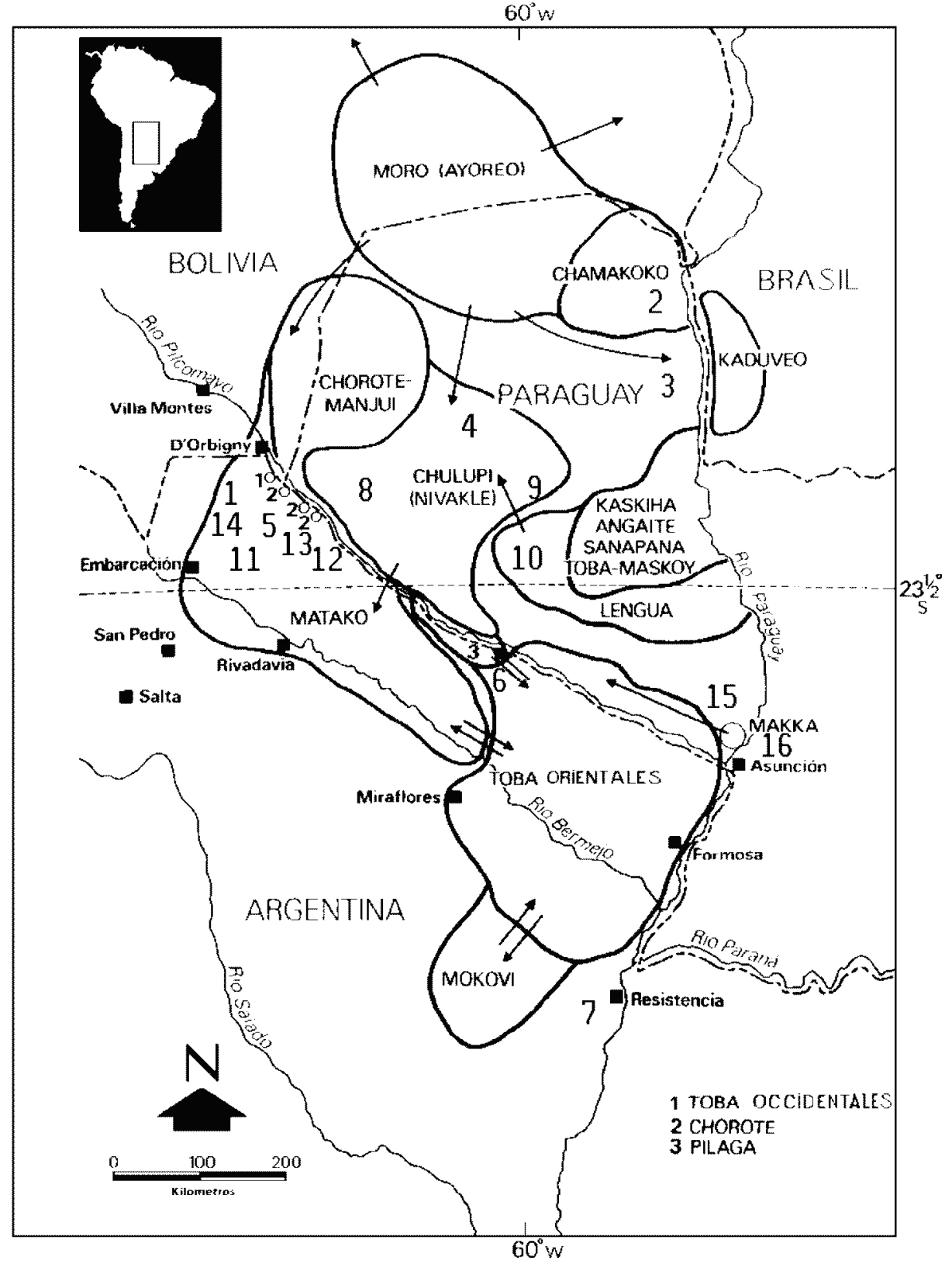


así llamadas "Urkulturen", y E. Palavecino entre las "Protoculturas"; para ello se habría basado -creemos- en la terminología de Schmidt. (Palavecino, Enrique, 1977: Cap. 1) A partir de la publicación del Handbook of South American Indians editado por J. Steward se las ubica entre los "marginales" (Steward, J., 1946; esp. Métraux). Hoy suele hablarse de los grupos de referencia con las denominaciones algo generales de "chaquenses típicos" -también utilizada por E. Palavecino-, "paleochaqueños" y "cazadores-recolectores del Chaco". Fernando Pagés Larraya objetó la fundamentación lingüística de la clasificación de los grupos étnicos del Chaco en la consideración de que ninguna descripción conocida de las lenguas vernáculas del Chaco aparece como indiscutible desde el punto de vista de la lingüística moderna. No obstante ello, admite que a través del tiempo, “....se ha mantenido la clasificación mencionada, valorando coincidencias que afirmaban ese proyecto intuitivo de agrupación"( Pagés Larraya, 1982, T. II: 1). Actualmente se ha generalizado el uso de una clasificación en seis grupos lingüísticos que a veces se consideran "familias de lenguas", aunque las relaciones entre sus componentes distan de haber sido estudiadas lo suficiente como para permitir la determinación de ese carácter. Estos grupos, y las etnias que les son adjudicadas, son los siguientes: 1-Zamuco: Ayoreo y Chamacoco; 2-Mataco-Maka: Mataco, Maká, Chorote y Chulupí; 3-Guaycuú •: Toba, Mocoví y Pilagá; 4-Maskoy: Lengua, Angaité, Sanapaná y Guaná; 5-Tupi-Guaraní: Chiriguano, Chané y Tapiete, y 6-Lule-Vilela: Vilela.

\section{Conclusiones}

El paisaje físico y humano que hemos intentado bosquejar en sus rasgos más generales, no tiene, sin embargo, la homogeneidad que una descripción somera y, en cierto modo "pictórica" como la que aquí se ofrece al lector puede llevar a colegir. Por el contrario, hemos querido insinuar, a lo largo del texto precedente, algo que por la misma forma de la descripción es muy difícil de expresar con precisión. Esto es, que las variaciones afectan gradientes sutiles, al modo de las unidades ecológicas, y muchas veces es difícil establecer claras líneas divisorias entre ellas. El ecólogo (Morello, op. cit. pp. 1-3) firmó que "las gradientes ecológicas fundamentales del Chaco (topográficas, pluviométricas, de continentalidad, edáficas) son de dirección este-oeste, es decir las macrocatenas esenciales tienen siempre ese sentido y en él se pueden estudiar las variantes correlativas en función de topografía o de pluviometría, etc.". Algo similar puede afirmarse en el plano de la cultura que, insensiblemente, realiza los ajustes que el medio exige, disimulando las diferencias de origen histórico. La capacidad de adaptación de las culturas chaqueñas es muy marcada; inclusive la organización social de estos indígenas puede adaptarse a las situaciones más variadas. Los grupos que lograron establecer su asiento junto a los ríos tuvieron en la pesca una actividad predominante e integrada; los que nomadizaban en las amplias sabanas pudieron basar su subsistencia sobre el aprovechamiento máximo del ñandú y de otros animales; los que vivían en las áreas más desérticas se adaptaron a un módulo en el que la recolección se convirtió en el recurso central y más significativo. Ya Métraux, al referirse a las sociedades chaqueñas que dividió según sus modelos históricos (Métraux, 1946, p. 301 y ss.) parece haber advertido que las diferentes formas de apropiación del territorio y los 
géneros de vida eran variables que la sociedad chaqueña toleraba mediante rápidos ajustes dependientes. Los dos grandes modelos que surgieron a partir del de nómades esteparios en tiempos históricos, esto es, el de salteadores a caballo y el de piratas en canoas, no manifestaban poseer diferencias esenciales con el primero, sino de grado, cambios en la demografía, e intensificación de principios de diferenciación social. Al desaparecer, por las cambiantes condiciones que surgieron históricamente en el Chaco, las situaciones que permitían la vida de acuerdo con esos modelos, algunas de las tribus que los habían adoptado regresaron rápidamente al módulo tradicional del nómade estepario, mientras que las que habían avanzado más en el proceso de especialización sufrieron la nueva situación muchas veces hasta el límite mismo de su extinción definitiva. Un lingüista de la sagacidad de A. Tovar vió en las lenguas chaqueñas (Tovar, 1961, p.195) exponentes de un tipo "informe, como hablaba Steinthal"; sin duda, no era su intención señalar la imposibilidad de elaborar un modelo gramatical de las mismas, sino antes bien, que sus formas "atentan contra nuestra conciencia lingüística". Creemos que debe buscarse la razón de esta polémica (Viñas Urquiza, 1974, I, p.156) atribución clasificatoria relacionándola con el alto poder dinámico y generativo de estas lenguas. Ciertas investigaciones de genética de población en el Chaco (Neel y Salzano, 1967; Salzano, 1970, p.2; Pérez Diez y Salzano, 1975) y otras regiones americanas resuelven un problema semejante hablando de un canon demográfico de "fusión-fisión" correspondiente a un estadio de cazadores y recolectores que también podría identificarse con el "viejo tronco" (Radin). Estas consideraciones resultan absolutamente coherentes con nuestras propias investigaciones de sociología etnográfica en el Chaco (Braunstein, 1978). Cada banda puede pasar años viviendo de acuerdo con una forma de subsistencia predominante y ajustada mas, al modificarse las condiciones del medio, responderá rápidamente con la adaptación a otro módulo completamente diferente. Los chaqueños han sabido adaptar con relativo éxito sus culturas montaraces a un ambiente de barriadas periurbanas. Ello ha sucedido -y sucede con rapidez creciente- en la mayoría de las ciudades de la región, como también en algunas considerablemente alejadas de ella. La tradición de la etnografía quiere ver una "cultura pobre" donde nosotros hablaríamos de "formas culturales poco especializadas", "protomorfas", o inclusive "proteicas". Esto nos conduce de algún modo al problema del antiguo hombre americano que es el problema de su uniforme diversidad.

\section{Bibliografía}

Agar, W.E., 1991. "Extracts from Papers Read before the Scottish Geographical Society, January, 1892". En: Grubb, W.B. An Unknow People in an Unknow Land. Apendix II: Geological Structure. Climate, Fauna and Flora of the Chaco, Part. I, pp. 305-309. London.

Aparicio, Francisco de y Horacio A. Difrieri, 1958/63. La Argentina; Suma de geografía. Peuser, 9 v. Buenos Aires.

Arenas, Pastor, 1981. Etnobotánica lengua-maskoy. Fundación para la Educación, la Ciencia y la Cultura. Buenos Aires

Braunstein, José, 1983. Algunos rasgos de la organización social de los indios del Gran Chaco. Trabajos de Etnología II, F.F. yL. -UBA, Buenos Aires.

Burgos, Juan, 1970. "El clima de la región Noroeste de la República Argentina en relación con la 
vegetación natural y el suelo". Boletín de la Sociedad Argentina de Botánica. Volumen XI. Suplemento de Septiembre dedicado a las IX Jornadas Argentinas de Botánica. Buenos Aires. Cabrera, Angel, 1970. La vegetación del Paraguay en el marco fitogeográfico de América del Sur. Boletín de la Sociedad Argentina de Botánica. Volumen XI, suplemento, Buenos Aires.

Cabrera, Angel y Abraham Willink, 1973. "Biogeografía de América Latina". O.E.A. Serie de biología. Monografía $\mathrm{N}^{\circ} 13$. Washington.

Cabrera, Angel y José Yepes, 1960. Mamíferos sud Americanos. 2a edic. Ediar. Buenos Aires.

Frenguelli, Joaquín, 1946. "Las grandes unidades físicas del territorio argentino". Geografía de la República Argentina. GEA, V. III. Buenos Aires.

Kerr, J. Graham, 1911. Extracts from “A Zoological Expedition to South America”. En: Grubb, W. B., "An unknown people in an Unknown Land". Part. II, pp. 310-317. London.

Krausse, Domingo, 1909. "Límites argentino-paraguayos. Estudio del Pilcomayo. Informe Memoria". Boletín del Instituto Geográfico Argentino, T. XXIII, no 1-12, pp. 86-162. Bs. As.

Marlange, M., 1972. Contribution á l'étude Phyto-ecologique du Chaco Argentin. Thése présentée devant l'Université des Sciences et Techniques du Languedoc. Montpellier. 2 Vol.

Métraux, Alfred, 1946. Ethnography of the Chaco. En: Steward, J. Handbook of the South American Indians. Bulletin of the Bureau of American Ethnology No 135; I, pp. 197-370. Washington.

Morello, Jorge, 1968. "Las grandes unidades de vegetación y ambiente del Chaco Argentino. Primera parte: Objetivos y metodología". La vegetación de la República Argentina, V. X. I.N.T.A., Buenos Aires.

Neel, J. y Salzano, Francisco, 1967. "Further Studies on the Xavante Indians. X. Some hipotheses-generalizations resulting from these studies". American Journal of Human Genetics, 19, pp. 554-574.

Pages Larraya, Fernando, 1982. Lo irracional en la cultura. FECIC

Palavecino, Enrique, 1948. "Areas y capas culturales en el territorio argentino". GAEA, t. VIII, pp. 447-523. Buenos Aires.

Perez Diez, Andrés y Francisco Salzano, 1977. "Evolutionary Implications of the Ethnography and Demography of Ayoreo Indians". Journal of Human Evolution. London.

Ragonese, Arturo y Julio Castiglioni, 1970. "Vegetación del parque chaqueño". Boletín de la Sociedad Argentina de Botánica. Volumen XI, Suplemento, Bs. As.

Ringuelet, Raúl, 1970. "Panorama general de la fauna y de sus relaciones ecológicas del Noreste Argentino y del dominio subtropical”. Boletín de la Sociedad Argentina de Botánica. Volumen XI, Suplemento, Buenos Aires.

Salzano, Francisco, 1970. "Genetic aspects of the Demography of American Indians and eskimos". Burg Wartenstein Symposium $N^{o}$ 50. Wenner-Gren Foundation for Anthropological Research.

New York.

Schimed, Adalberto, 1909. "Expedición de Adalberto y Arnaldo Schimed a la región de los Ríos Pilcomayo y Confuso, en los años 1906 y 1907”. Boletín del Instituto Geográfico Argentino, T. XXIII, No 1-12, pp.58-85, Bs. As.

Steward, Julian, 1946. "Handbook of South American Indians". Bulletin of the Bureau of American Ethnology $\mathrm{N}^{\mathrm{o}} 135$, Vol. I.

Tapia, Augusto, 1935. Pilcomayo. Contribución al conocimiento de las llanuras argentinas. Publ. Ministerio de Agricultura de la Nación, Dirección de Minas y Geología, Bs.As.

Thouars, E.A.. 1909a. "Geographie du Rio Pilcomayo". Boletín de la Sociedad Geográfica Argentina. TXXIII, No 1-12, pp. 25-31, Bs.As.

Thouars, E.A.. 1909 b. "Hidrographie du Pilcomayo". Ibid.pp. 32-33 
Thouars, E.A.. 1909 c. "Discussion Raisonnée de la Geographie du Pilcomayo". Ibid., pp. 33-40 Thouars, E.A.. 1909 d. "Considerations Generales sur les Explorations du Pilcomayo". Ibid., pp.41-97 Tovar, Antonio, 1961. Catálogo de las lenguas de América del Sur. Sudamericana. Buenos Aires Vellard, Jehan Albert. 1972. Les Indiens Ayoveo du Grand Chaco. Note (Séance du 29 mai 1972) de M. Jean Veallard, présentée par M. Jacques Millot. C. R. Acad. Sc. Paris, p. 3245-3247 (12 juin 1972), Série D.

Vellard, Jehan Albert. 1981. "Introducción al estudio biométrico de las poblaciones indígenas del Chaco". Scripta Ethnologica, VI, Buenos Aires, pp. 155-162.

Viñas Urquiza, María, 1974. "Lengua Mataca". Archivo de lenguas Precolombinas, 2, Facultad de Filosofía y Letras (U.B.A.), Buenos Aires.

Wilbert, Johannes y Kareen Simonneau, 1982. Folk literature of the Toba Indians. UCLA

\title{
Resumen
}

Es intención de los autores ofrecer elementos de juicio que contribuyan a que la información referida a los grupos indígenas del Gran Chaco que se encuentra en la literatura existente resulte mas fácilmente comprensible, tanto desde el punto de vista espacial como temporal.

Para ello han bosquejado simultáneamente los aspectos fisiográficos del ámbito chaqueño y aquellos rasgos culturales propios de sus indios que demuestran poseer una marcada adaptación a ese medio geográfico.

En primer lugar se efectúa una caracterización de la región que incluye sus límites, divisiones, tipos de clima, su flora y su fauna.

Se sintetizan luego las actividades de caza, pesca, recolección y agricultura características de la cultura tradicional de los indígenas chaqueños.

Finalmente se presenta una descripción somera de la organización social de los aborígenes en cuestión, al tiempo que se hace referencia a las modificaciones que la misma ha sufrido durante el transcurso del tiempo.

$<$ Gran Chaco $><$ Geografía $><$ aborígenes $><$ organización social $>$

\begin{abstract}
It is the purpose of the authors to offer elements of judgement in order to make the information referred to the groups of natives of the 'Gran Chaco' contained in the actual literature more comprehensible, from the point of view of time and space.

To achieve this, they have sketched (outlined) the physiographical aspects of the chaqueña region, together with those cultural features inherent in the natives who show to possess a remarkable adaptation to that invironment.

In the first place, a characterization of the region is performed, including limits, divisions, types of climate, flora and fauna.

Secondly, the activities related to hunting, fishing, recollection and agriculture of the traditional culture of these chaqueños indians are synthesized.

Finally, a mere description of the social organization is presented, as well as a reference to the modification this organization has undergone through the course of time.
\end{abstract}

$<$ Gran Chaco $><$ Geography $><$ Indians $><$ social organization $>$ 